\title{
Análise de regressão da lesão periapical: relato de caso clínico
}

\author{
Periapical lesion regression analysis: clinical case report \\ Análisis de regresión de lesiones periapicales: reporte de caso clínico
}

Recebido: 06/09/2021 | Revisado: 12/09/2021 | Aceito: 16/09/2021 | Publicado: 18/09/2021

Rosana Maria Coelho Travassos

ORCID: https://orcid.org/0000-0003-4148-1288

Universidade de Pernambuco, Brasil

E-mail: travassos.rosana@gmail.com

Ana Caroline Chalegre de Oliveira

ORCID: https://orcid.org/0000-0003-3841-2900

Universidade de Pernambuco, Brasil

E-mail: caroline.chalegre@upe.br

Charley Henrique dos Passos Gomes Filho

ORCID: https://orcid.org/0000-0002-1917-6335

Universidade de Pernambuco, Brasil

E-mail: charley.henrique@upe.br

Ismael Sebastião da Silva Sousa

ORCID: https://orcid.org/0000-0002-7947-8933

Universidade de Pernambuco, Brasil

E-mail: ismaellsebastiao@hotmail.com

José Mateus da Silva Alves

ORCID: https://orcid.org/0000-0001-9189-6452

Universidade de Pernambuco, Brasil

E-mail: mateus.alves@upe.br

Kataryne Maria dos Santos

ORCID: https://orcid.org/0000-0003-3720-3955

Universidade de Pernambuco, Brasil E-mail: kataryne.msantos@upe.br

Matheus Eduardo da Silva Paz

ORCID: https://orcid.org/0000-0002-5491-1980 Universidade de Pernambuco, Brasil E-mail: matheus.paz@upe.br

Victor Felipe Farias do Prado

ORCID: https://orcid.org/0000-0002-9790-8001 Universidade de Pernambuco, Brasil E-mail: victor.prado@upe.br

\begin{abstract}
Resumo
Este estudo possui como objetivo a descrição do reparo através de um caso clínico de uma lesão periapical difusa e extensa com diagnóstico sugestivo de abscesso periapical crônico. Foram realizados a anamnese e exame clínico. A partir da correta indicação do tratamento endodôntico, foi realizada a abertura coronária e posterior preparo cervical com brocas GattesGlidden, e no preparo cervico-medial, os instrumentos manuais tipo K-Files. Posteriormente, introduziu-se a medicação intracanal à base de hidróxido de cálcio. Após o preparo do canal radicular, o paciente foi submetido a medicação intracanal constituida por hidróxido de cálcio. Após 15 dias, foi constatada a ausência da sensibibilidade referida no início da terapêutica e portanto seguiu-se com a obturação do sistema de canais com a técnica de condensação lateral ativa juntamente com cimento AH-Plus. Foi averiguado por imagens radiográficas no tratamento realizado, que no decorrer das consultas houve uma redução no diâmetro da lesão periapical. Essa redução foi ocasionada por conta da medicação intracanal, que foi renovada a cada mês por um período de seis meses com a finalidade de desinfetar o canal radicular e causar reparação da destruição óssea periapical. Diante disso, a proservação clínica e radiográfica, após um período de seis meses de medicação intracanal, constatou o reparo da lesão periapical.
\end{abstract}

Palavras-chave: Endodontia; Doenças periapicais; Tratamento do canal.

\begin{abstract}
This study aims to describe the repair through a clinical case of a diffuse and extensive periapical lesion with suggestive diagnosis of chronic periapical abscess. Anamnesis and clinical examination were performed. Based on the correct indication for endodontic treatment, coronary opening and subsequent cervical preparation were performed with GattesGlidden drills, and K-Files type manual instruments were performed in the cervico-medial preparation. Subsequently, intracanal medication based on calcium hydroxide was introduced. After preparing the root canal, the
\end{abstract}


patient underwent intracanal medication consisting of calcium hydroxide. After 15 days, the absence of the sensitivity referred to at the beginning of therapy was verified and, therefore, the canal system was filled with the active lateral condensation technique together with $\mathrm{AH}$-Plus cement. It was verified by radiographic images during the treatment performed, that during the consultations there was a reduction in the diameter of the periapical lesion. This reduction was caused by the intracanal medication, which was renewed every month for a period of six months in order to disinfect the root canal and repair the periapical bone destruction. Therefore, the clinical and radiographic follow-up, after a period of six months of intracanal medication, found the repair of the periapical lesion.

Keywords: Endodontics; Periapical diseases; Root canal.

\section{Resumen}

Este estudio tiene como objetivo describir la reparación a través de un caso clínico de una lesión periapical extensa y difusa con diagnóstico sugestivo de absceso periapical crónico. Se realizó anamnesis y exploración clínica. Con base en la correcta indicación de tratamiento endodóntico, se realizó la apertura coronaria y preparación cervical posterior con fresas GattesGlidden, y se realizó instrumental manual tipo K-Files en la preparación cérvico-medial. Posteriormente, se introdujo la medicación intracanal a base de hidróxido de calcio. Después de preparar el conducto radicular, el paciente se sometió a medicación intracanal consistente en hidróxido de calcio. A los 15 días se constató la ausencia de la sensibilidad referida al inicio de la terapia y, por tanto, se rellenó el sistema de canales con la técnica de condensación lateral activa junto con cemento AH-Plus. Se verificó mediante imágenes radiográficas durante el tratamiento realizado, que durante las consultas hubo una reducción del diámetro de la lesión periapical. Esta reducción fue provocada por la medicación intracanal, que se renovó cada mes por un período de seis meses con el fin de desinfectar el conducto radicular y reparar la destrucción ósea periapical. Por tanto, el seguimiento clínico y radiográfico, tras un período de seis meses de medicación intracanal, encontró la reparación de la lesión periapical.

Palabras clave: Endodoncia; Enfermedades periapicales; Tratamiento de conducto.

\section{Introdução}

Alterações pulpares podem ser originadas através de influência química, física e principalmente bacteriológica (Kirchhoff; Viapiana \& Ribeiro, 2013), tais alterações possuem a capacidade de violação da integridade pulpar e aparecimento de doença pulpar e periapical (Zoti \& Hartmann, 2016). As Bactérias anaeróbicas, particularmente espécies gram-negativas, são associadas aos sinais e sintomas de doença periapical (Gomes. et al., 1996).

Neste caso, a sucessão de injúrias presentes dentro do canal radicular poderá culminar numa necrose pulpar que se caracteriza pela suspensão das funções vitais da polpa que caso não seja tratada de imediato, possui um potencial de contaminação bacteriana no osso alveolar gerando, portanto, alterações ósseas periapicais (Kirchhoff; Viapiana \& Ribeiro, 2013).

Para tal, o tratamento endodôntico é considerado a terapêutica de primeira escolha e possui como objetivo o preparo químico-mecânico dos canais radiculares que deve ser capaz de remover completamente as camadas de dentina contaminada e permitir que o irrigante alcance todo o espaço do canal. Este procedimento visa reduzir o número de bactérias, que são um importante fator de risco para a persistência da doença periapical após o tratamento do canal radicular (Siqueira, JR., 2003).

O tratamento endodôntico torna-se de extrema importância pois permite a prevenção ou tratamento da periodontite apical através da limpeza, modelagem, e obturação de sistemas de canais radiculares e uma posterior cicatrização adequada. (Almeida; et al., 2011). A instrumentação do canal radicular permite que soluções de irrigação e medicamentos antibacterianos alcancem todo o espaço da canal radicular com o intuito de preservar a integridade do canal (Galvão, 2012). Contudo, é importante ressaltar que todo tratamento endodôntico almeja tocar em todas as paredes do canal radicular uma vez que áreas não tocadas são regiões que abrigam restos de biofilmes bacterianos e tecido pulpar (Lopes \& Siqueira Júnior, 2013) e apesar dos avanços técnicos na endodontia, o preparo do canal radicular ainda é altamente influenciado pela anatomia do mesmo (Siqueira.,. et al. 1997). 
O processo de obturação do canal radicular constitui, portanto, uma fase extremamente importante pois terá como objetivo selar toda o canal radicular impedindo a contaminação bacteriológica e reinfecção dos canais radiculares. (Fritz, 2017).

As lesões traumáticas não seguem a progressão tradicional e podem ocorrer diretamente em qualquer nível dos tecidos dentais ou perirradiculares. Assim, podem ocorrer especialmente na polpa, no cemento, no ápice da raiz, no ligamento periodontal ou no osso adjacente, de forma individual ou combinada (Ricucci, et al., 2015; Fouad, 2019).

As intervenções endodônticas após lesões traumáticas são contempladas após um período de observação quando o dente mostra sinais e sintomas de necrose pulpar. Durante esse período de retardo, mais invasão bacteriana pode ocorrer, levando ao surgimento de lesões periapicais e reabsorções (Fouad, 2019).

Lesões periapicais extensas podem ocorrer em dentes traumatizados e definir sua conduta terapêutica é extremamente desafiador. Muitos profissionais consideram a intervenção cirúrgica como primeira escolha de tratamento. No entanto, atualmente, há uma tendência para se optar por tratamentos conservadores, reservando as intervenções cirúrgicas para casos em que a lesão persiste (Mitra, et al., 2017).

Tal estudo possui como objetivo constatar o processo reparatório dos tecidos que circundam o ápice dentário logo após o tratamento endodôntico convencional em paciente portador de alteração periapical sugestiva de abcesso dento alveolar crônico.

\section{Metodologia}

O presente artigo trata-se de um relato de caso clínico, descritivo e qualitativo, em que se observa o tratamento conservador de uma lesão periapical extensa asséptica. Quanto aos termos éticos, o paciente assinou o Termo de consentimento Livre e Esclarecido e foram respeitados os princípios éticos descritos na Declaração de Helsinque (Pereira et al., 2018).

\section{Relato de Caso Clínico}

Paciente A.A.G.L., leucoderma, sexo feminino, 40 anos, foi encaminhada para a Clínica de Atenção Básica III da Faculdade de Odontologia de Pernambuco, em Camaragibe, PE, Brasil, para avaliação da necessidade de tratamento endodôntico no dente 42 .

$\mathrm{Na}$ anamnese, não foi relatado qualquer alteração de saúde sistêmica. No exame físico foi verificada ausência de edema e presença de fístula inativa (Figura 1), sem mobilidade, não respondeu ao teste de sensibilidade pulpar, nem à percussão vertical e horizontal.

A partir da radiografia inicial (Figura 2) e panorâmica (Figura 3) foram observadas extensa radiotransparência periapical bem como, uma área radiopaca na coroa sugestiva de restauração sem invasão da câmara pulpar. O diagnóstico sugestivo foi de abscesso periapical crônico, sendo, assim, indicado o tratamento endodôntico não cirúrgico com a finalidade de obter o reparo da destruição óssea periapical. 
Research, Society and Development, v. 10, n. 12, e201101220267, 2021

(CC BY 4.0) | ISSN 2525-3409 | DOI: http://dx.doi.org/10.33448/rsd-v10i12.20267

Figura 1. Exame físico.

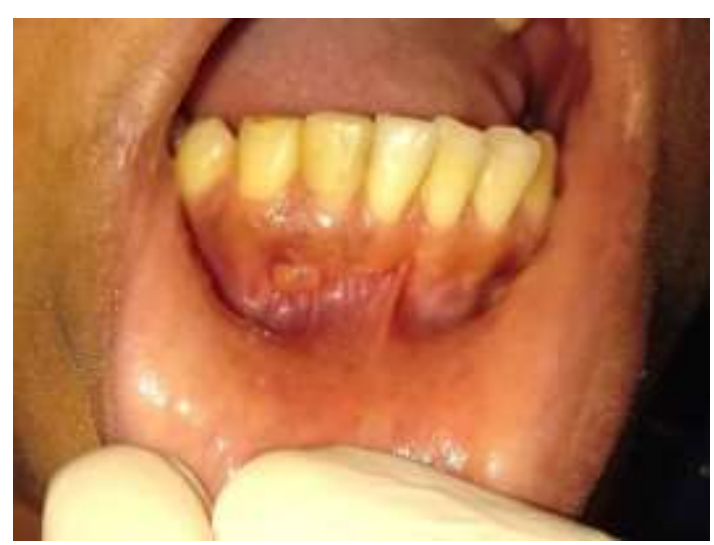

Fonte: Autores.

Todos as áreas devem ser examinadas. Na imagem acima, evidencia-se uma alteração na região do dente suspeito e, portanto, segue as manobras diagnósticas radiográficas.

Figura 2. Exame radiográfico inicial.

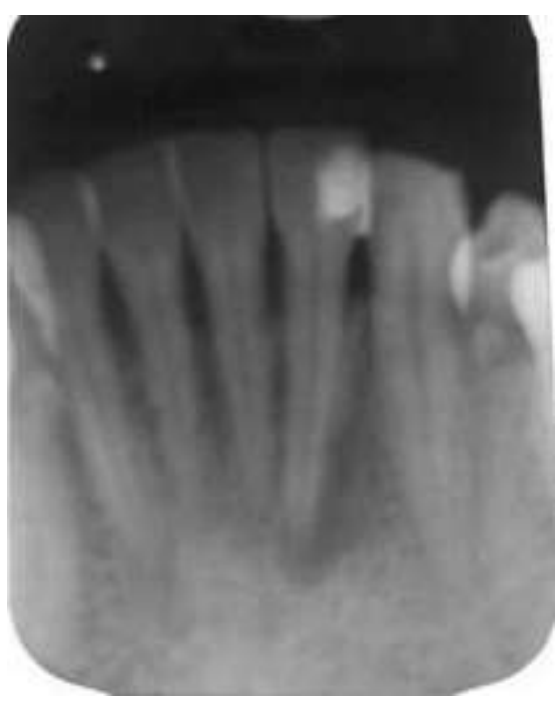

Fonte: Autores.

A partir do exame radiográfico inicial, evidencia-se uma área radiotansparente na região de periápice do dente 42 e uma área radiopaca extensa na coroa dentária sugestiva a material restaurador. 
Figura 3. Radiografia panorâmica

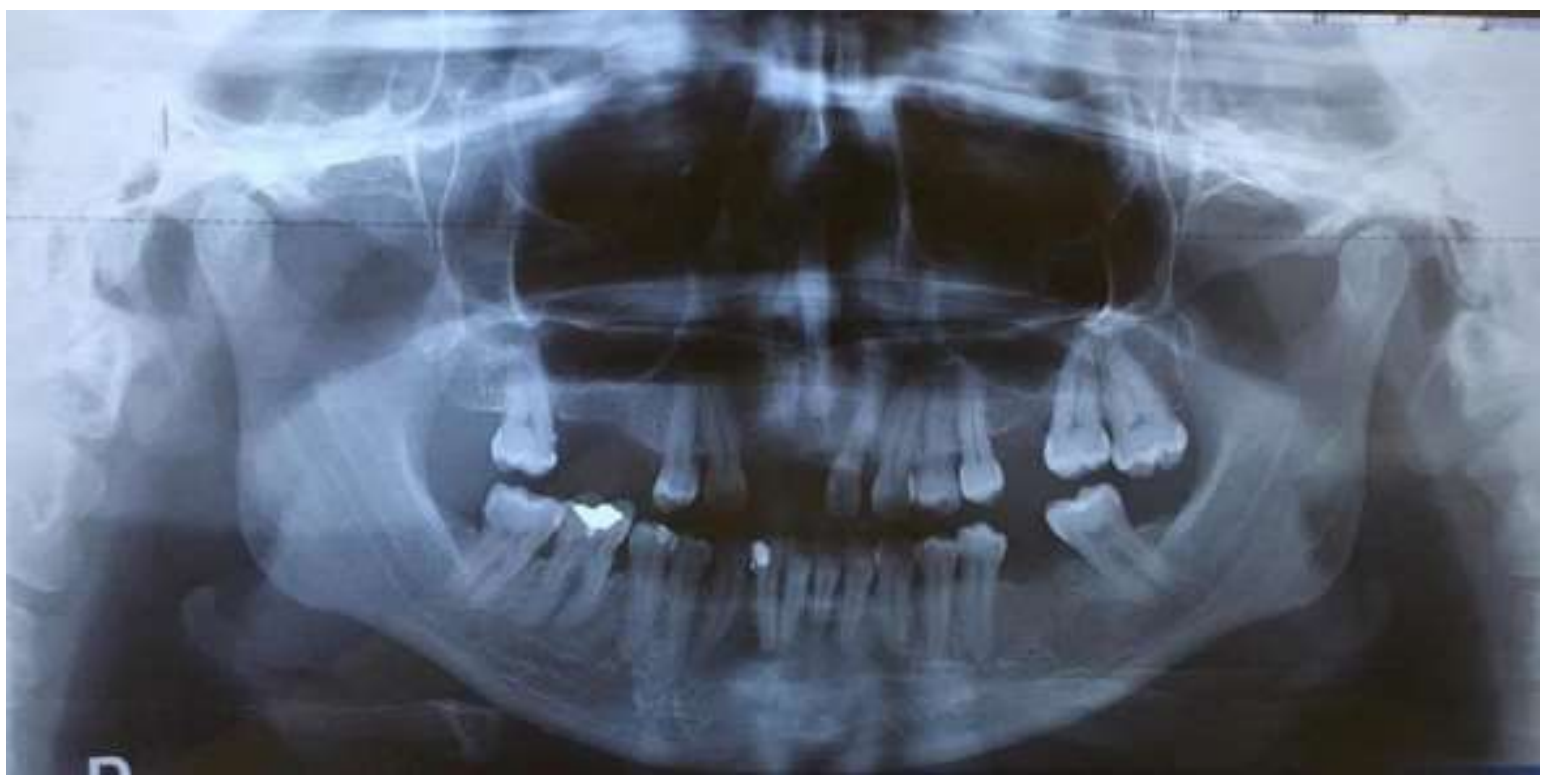

Fonte: Autores.

Após os procedimentos de antissepsia foi realizada anestesia do nervo alveolar inferior, seguido de isolamento absoluto e remoção do tecido cariado com broca esférica n 2 (KGSorensen, Cotia-SP, Brasil) em alta-rotação, posteriormente foi realizada a abertura coronária seguida de irrigação com solução de NaOCL a 2,5\% e a exploração do canal com instrumento tipo K \# 15 (Dentsply-Meillefer). O preparo coroa-ápice sem pressão: preparo cervical com as brocas Gattes Glidden em ordem decrescente de números 5, 4 e 3 irrigando com solução de NaOCL a 2\%. O preparo cervico-medial com instrumentos manuais tipo K-Files (Dentsply-Meillefer®), em ordem decrescente: $2^{a}$ Série, \# 80/\#70/\#60/\#55/\#50, a cada troca de instrumento realizou-se irrigação abundante com solução de NaOCL a $2 \%$. Ao atingir o comprimento de $2 \mathrm{~mm}$ aquém do ápice radicular, realizou-se a odontometria para a determinação do Comprimento Real de Trabalho e Comprimento Real do Dente. O término do preparo apical foi feito até a lima de número $60 \mathrm{~K}$-File, posteriormente, foi introduzido EDTA por 3 minutos e a irrigação final foi realizada com hipoclorito de sódio a 2,5\%. Após secagem do canal com pontas de papel absorvente, foi colocada medicação intracanal à base de hidróxido de cálcio (UltraCal@ XS) e selamento provisório com cimento de ionômero de vidro (Vitro Fil - DFL®).

A medicação intracanal foi renovada mensalmente por um período de 6 meses, com o objetivo de observar a regressão da lesão periapical. Constatando ausência de desconforto e regressão parcial da lesão periapical, realizou-se a prova do cone através de radiografia periapical (Figura 4) e em seguida foi realizada a obturação do sistema de canais, com cimento endodôntico AH Plus (Dentsply) juntamente com a técnica de condensação lateral, a restauração definitiva (Figura 5) do elemento dentário foi realizada com Resina Composta (Opallis- FGM). 
Research, Society and Development, v. 10, n. 12, e201101220267, 2021

(CC BY 4.0) | ISSN 2525-3409 | DOI: http://dx.doi.org/10.33448/rsd-v10i12.20267

Figura 4. Radiografia periapical.

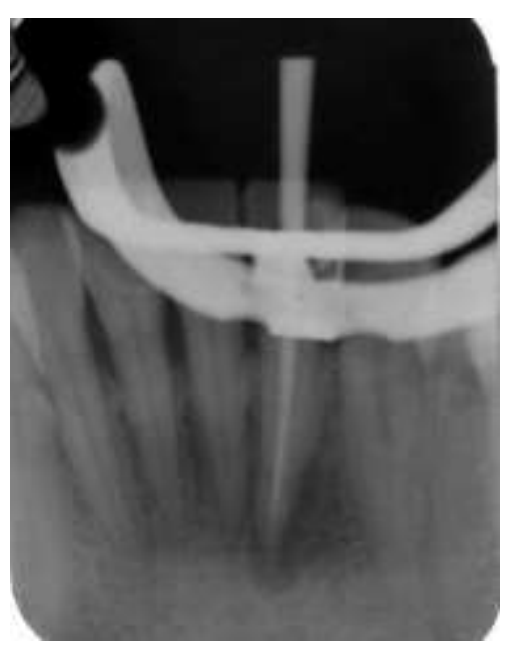

Fonte: Autores.

Na fase de obturação, têm-se a confirmação da adaptação do cone no comprimento real de trabalho como mostrada na figura acima.

Figura 5. Restauração definitiva.

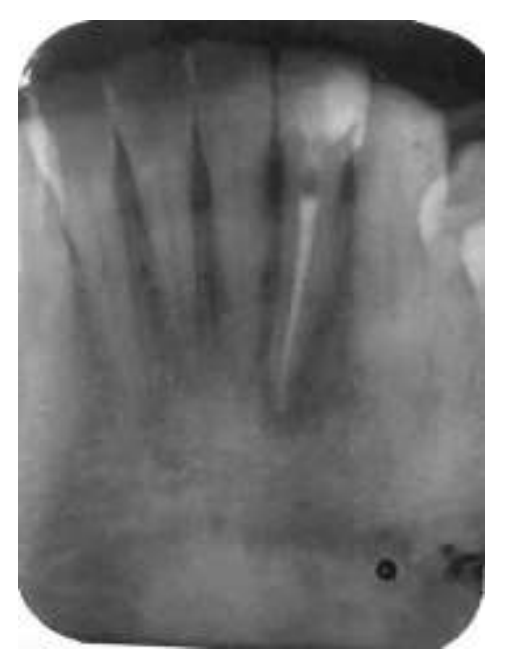

Fonte: Autores.

Aspecto imediato pós-obturação do canal radicular, contatando o preenchimento das paredes radiculares com material obturador e cimento endodôntico. 
Figura 6. Exame radiográfico após 6 meses.

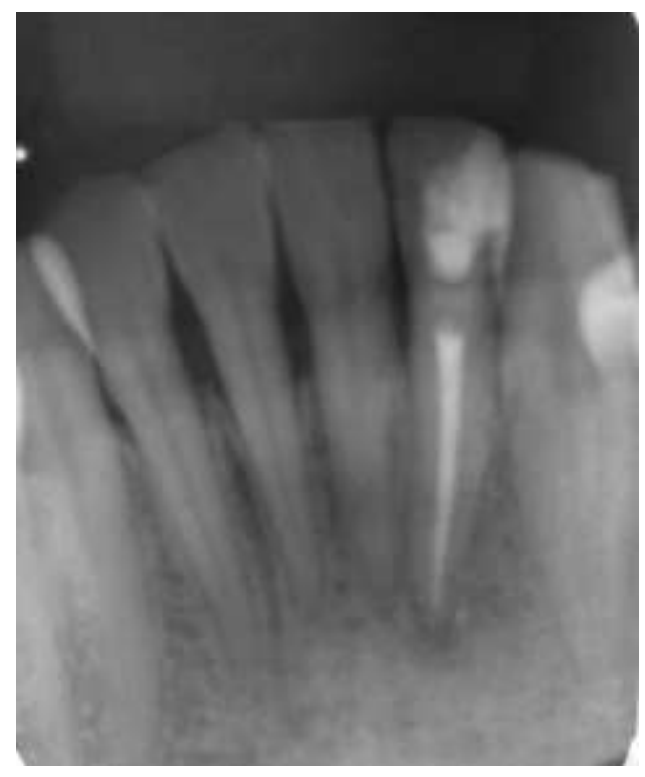

Fonte: Autores.

$\mathrm{Na}$ consulta de proservação, após seis meses da obturação do canal radicular, foi realizado o exame clínico e radiográfico, demonstrando o reparo da lesão periapical (Figura 6.).

\section{Discussão}

Em processos infecciosos de longa duração visualiza-se a ocorrência de uma seleção natural levando a predominância de microrganismos anaeróbicos especialmente gram negativos que apresentam endotoxinas em sua parede celular (Silva, 2002). Tais endotoxinas são liberadas durante a duplicação ou morte bacteriana proporcionando uma série de reações inflamatórias e reabsorções ósseas (Barthel, C.R. et al., 1997).

Destes processos, destaca-se o abscesso periapical crônico que é uma lesão assintomática e de evolução lenta, resultante de infecção pulpar por cárie dentária, restauração extensa, traumatismos ou problemas no tratamento endodôntico. Radiograficamente, ele é observado como uma área radiotransparente de rarefação difusa no osso alveolar (KIRCHHOFF; VIAPIANA; RIBEIRO, 2013) e é caracterizado como periapicopatia inflamatória crônica, assim como os granulomas e cistos periapicais (Mitra A, et al., 2017).

A partir do correto diagnóstico, faz-se necessário a realização do tratamento endodôntico a fim de alcançar a resolubilidade a lesão periapical. Tal tratamento, por sua vez, perpassa pelo preparo químico-mecânico que constitui uma das etapas de maior importância uma vez que, possui o papel de realizar a limpeza e desinfeção dos microrganismos com posterior eliminação dos agentes irritantes que constituem fator etiológico da periodontite apical (Carvalho et al. 2019). Apesar do tratamento endodôntico convencional não cirúrgico ser a terapêutica de primeira escolha, há casos em que é preciso associá-lo com procedimentos mais invasivos como por exemplo a descompressão, marsupialização e a enucleação da lesão (Dandotikar, D. et al., 2013).

Visando aumentar as chances da completa resolução da lesão periapical, o tratamento endodôntico deve ser executado seguindo criteriosa instrumentação, irrigação farta e eficaz, realização da patência foraminal, além de um preparo biomecânico adequado além de medicação intracanal (Anusha. et al, 2017). 
Research, Society and Development, v. 10, n. 12, e201101220267, 2021

(CC BY 4.0) | ISSN 2525-3409 | DOI: http://dx.doi.org/10.33448/rsd-v10i12.20267

Um dos medicamentos intracanais bastante indicados é o hidróxido de cálcio, devido suas propriedades antiinflamatórias, antibacterianas de neutralização de produtos ácidos e ativação de enzimas (Siqueira Jr. et al., 2012).

\section{Considerações Finais}

Para o correto acompanhamento da conduta terapêutica, é de fundamental importância o registro radiográfico inicial, aspecto imediato e aspecto final através desses registros. O presente caso aborda a terapêutica de uma lesão periapical crônica através do tratamento endodôntico convencional não cirúrgico associado a medicação intracanal a base de hidróxido de cálcio. A partir do acompanhamento clínico e radiográfico, constatou-se a remissão da lesão e a efetividade do tratamento no sucesso terapêutico.

\section{Referências}

Almeida, A. G., Veloso, P. H., Sampaio, C. F., Oliveira, F. H., \& Freire, M. A. (2011). Qualidade das restaurações e o insucesso endodôntico. RevOdontol Bras Central. v. 20, n. 52, p. 74-78.

Anusha, B., Madhusudhana, K., Chinni, S. K., \& Paramesh, Y. (2017). Assessment of Pulp Oxygen Saturation Levels by Pulse Oximetry for Pulpal Diseases -A Diagnostic Study. J Clin Diagn Res. (9):ZC36-ZC39.

Barthel, C. R., Levin, L. G., Reisner, H. M., \& Trope, M. (1997). TNF-alpha release in monocytes after exposure to calcium hydroxide treated Escherichia coli LPS. Int Endod J. Oxford. 30(3), 155-9.

Carvalho, M. C. et al. (2019). Effectiveness of XP-Endo Finisher in the reduction of bacterial load in oval-shaped root canals. Brazilian Oral Research, v. 33, e021.

Dandotikar D, Peddi R, Lakhani B, Lata K, Mathur A, Chowdary UK. (2013). Nonsurgical management of a periapical cyst: a case report. $J$ Int Oral Health.; 5(3):79-84.

Fouad, A. (2019). Microbiological aspects of traumatic injuries. Dental Traumatology, 35(6), 324-332.

Fritz, A. L.C. (2017). Avaliação da qualidade dos tratamentos endodônticos, na etapada obturação, realizados por alunos de graduação. 67 f. Dissertação (Mestrado) - Curso de Odontologia, Universidade Federal do Espírito Santo, Vitória.

Galvão, T. P. (2012). Eficácia de três métodos para inserção de medicação intracanala base de hidróxido de cálcio em canais radiculares. 67 f. Mestrado em Endodontia - Faculdade de Odontologia da Universidade Estácio de Sá, Rio de Janeiro.

Gomes, B. P., Lilley, J. D., \& Drucker, D. B. (1996). Variations in the susceptibilities of components of the endodontic microflora to biomechanical procedures. Int Endod J. 29(4):235-41.

Kirchhoff, A. L., Viapiana, R., \& Ribeiro, R. G. (2013). Repercussões periapicais emdentes com necrose pulpar. RGO - Rev Gaúcha Odontol, Porto Alegre, v. 61, p.469-475.

Mitra, A., \& Adhikari, C. (2017). Management of large periapical lesions by non surgical endodontic approach-two case reports. IJIRDS, 2(5), 97104.

Lopes, H. P., Siqueira, J.F. (2010) Endodontia Biologia e Técnica.3 ${ }^{a}$ ed. Riode Janeiro: Guanabara Koogan.

Neville, B.W. (2016). Patologia oral e maxilofacial.4. ed. Rio de Janeiro: GuanabaraKoogan.

Ricucci, D., Siqueira J., Loghin S., \& Berman L. (2015). The cracked tooth: histopathologic and histobacteriologic aspects. J Endod, 41, 343-52.

Silva, L.A.B. et al. (2002). Effect of calcium hydroxide on bacterial endotoxin in vivo. J,Endod., New York, v, 28, p.94-98.

Siqueira. J.F., Araújo, M. C., Garcia, P. F., Fraga, R. C., \& Dantas, C. J. (1997). Histological evaluation of the effectiveness of five instrumentation techniques for cleaning the apical third of root canals. J Endod. 23:499-502

Siqueira, J. F., Alves, F. R., Versiani, M. A., et al. (2013) Correlative bacteriologic and microcomputed tomographic analysis of mandibular molar mesial canals prepared by selfadjusting file, reciproc, and twisted file systems. Journal of Endodontics 39, 1044-50

Siqueira, J. F., José, F. et al. (2012). Princípios biológicos do tratamento endodôntico de dentes com polpa necrosada e lesão perirradicular. Rev. Bras. Odontol. vol.69, n.1, pp. 8-14.

Siqueira. J. F. (2003) Microbial causes of endodontic flareups. International Endodontic Journal 36, 453-63

Zoti, M., \& Hartmann, M. S. M. (2016). Avaliação de tratamentos endodônticos realizadospor alunos de graduação da escola de odontologia da IMED. J Oral Invest, Passo Fundo, v. 5, n. 1, p. 4-12. 